\title{
Identification of Double Bond Positions in Dodecenyl Acetates by Electron Impact Mass Spectrometry
}

\author{
Michio HoriIKe and Chisato Hirano \\ Department of Agricultural Chemistry, Kochi University, \\ Nangoku, Kochi 783, Japan
}

Received November 9, 1981

\begin{abstract}
Seven positional isomers $\left(\Delta^{5} \sim \Delta^{11}\right)$ of dodecenyl acetate were analyzed, without any prior chemical modifications by combined gas-liquid chromatography-electron impact mass spectrometry. The position of the double bonds in the alkenes could be located by the relative intensities of the predominant fragment ions, depending upon whether or not the value of the ratio was over unity.
\end{abstract}

During the last two decades there has been a growing interest in the chemical identification and synthesis of insect sex pheromones in an effort to find better substitutes for insecticides, eventually aiming at successful pest control without hazard or pollution.

Female sex pheromones of many nocturnal moths have mostly proved to be unsaturated straight-chain aliphatic acetates, alcohols or their corresponding aldehydes. ${ }^{1)}$

Indeed gas-liquid chromatography-mass spectrometery (GCMS) studies provide a great deal of information as to the structural characteristics which affect the biological activity of pheromones; but the direct and unequivocal location of the double bond position in the alkenes has scarcely been attained by this means. A variety of techniques have been used to determine the double bond positions in alkenes, among which periodate-permanganate cleavage $^{2)}$ or ozonolysis ${ }^{3)}$ followed by gasliquid chromatography have been extensively applied to insect-derived alkenes. A major disadvantage inherent in these conventional techniques is the tedious separation and purification steps which are indispensable for analysis. It is even more difficult when the amount of material available is extremely small.

In the previous paper, ${ }^{4)}$ we reported an empirical approach to the location of double bonds in tetradecenyl acetates, without any prior chemical modifications, by electron impact mass spectrometry (EIMS). In order to test the generality of our previous findings, we extended our research to a series of alkenyl compounds which contain different carbon length and functional groups. The present paper deals with the spectra of seven positional isomers of dodecenyl acetate with the double bond at the $\mathrm{C}_{5} \sim \mathrm{C}_{11}$, which constitute the sex pheromones of the female cabbage looper moth, Trichoplusia $n i\left(\Delta^{7}\right),{ }^{5)}$ the male sex attractant of the oriental fruit moth, Grapholitha molesta $\left(\Delta^{8}\right),{ }^{6}$ the main component of the sex pheromone secreted by the female grape berry moth, Paralobesia viteana $\left(\Delta^{9}\right)^{7)}$ and etc.

\section{EXPERIMENTAL}

Six alkenyl acetates $\left(\Delta^{5} \sim \Delta^{10}\right)$ were synthesized by the Wittig reactions of ( $\omega$-hydroxyalkyl)triphenylphosphonium salt with alkanal followed by acetylation. ${ }^{8)}$ The geometrical distribution in these alkenyl acetates was no less than $90 \%$ of the $(Z)$-configuration. The acetate of $11-$ dodecenol was kindly supplied by Dr. H. Noguchi, National Institute of Agricultural Sciences, Tsukuba, Ibaraki, Japan. GCMS was performed five times with a Shimadzu-LKB 9000 gas chromatography-mass spectrometer interfaced with a computer data system (Shimadzu GCMS-PACK 90). The gas chromatographic inlet system was equipped with a $2 \mathrm{~m}$-coiled glass column of $1 \% \mathrm{OV}-1$ as the stationary phase. The helium flow rate was $30 \mathrm{ml} /$ min; column temperature $160^{\circ} \mathrm{C}$; separator temperature 

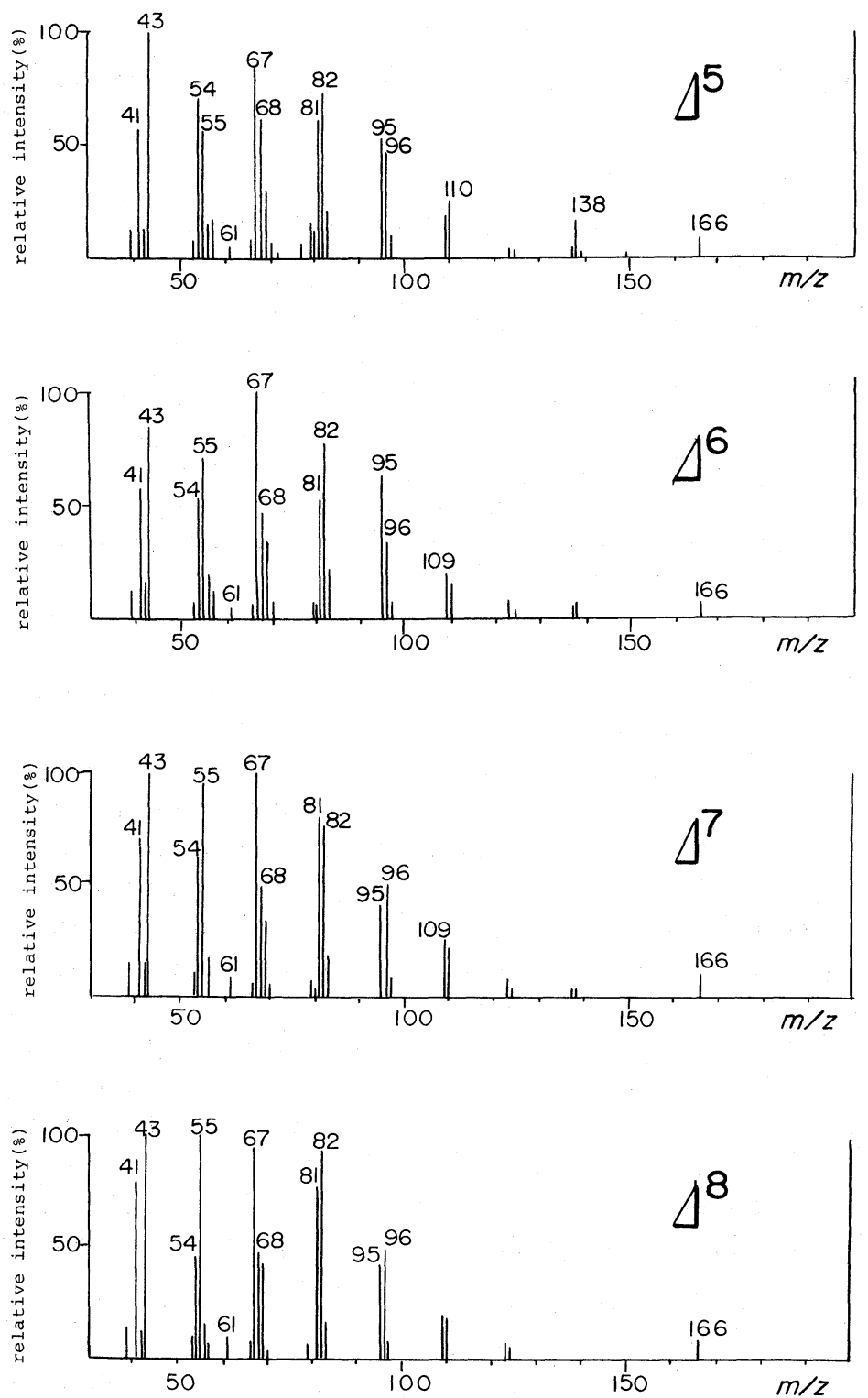

Fig. 1.

$230^{\circ} \mathrm{C}$; ion source temperature $290^{\circ} \mathrm{C}$. Ionizing potential was changed over a range of 20 to $70 \mathrm{eV}$, the emission current was $60 \mu \mathrm{A}$ and the accelerating voltage was $3.5 \mathrm{kV}$. The mass spectra were recorded on the apex of the gas chromatographic peak. The scan speed was 7. A JEOLJMS-D300 spectrometer was employed as double focusing instrument.

\section{RESULTS AND DISCUSSION}

Figure 1 shows the typical mass spectra of seven isomeric dodecenyl acetates at $70 \mathrm{eV}$ of ionization energy with a Shimadzu-LKB 9000 system.

The spectra of all isomers showed no appreciable molecular ions, but the ion of the highest $m / z$ value observed was indicated at $m / z 166$, which may probably be the fragment ion derived from the loss of acetic acid moiety from the molecular ion. The $\Delta^{5}$ - and $\Delta^{11}$. isomers had base peaks at $m / z 43, \Delta^{6}$-isomer at $\mathrm{m} / \mathrm{z} 67$, and both $\Delta^{9}$ - and $\Delta^{10}$-isomers at $\mathrm{m} / \mathrm{z}$ 

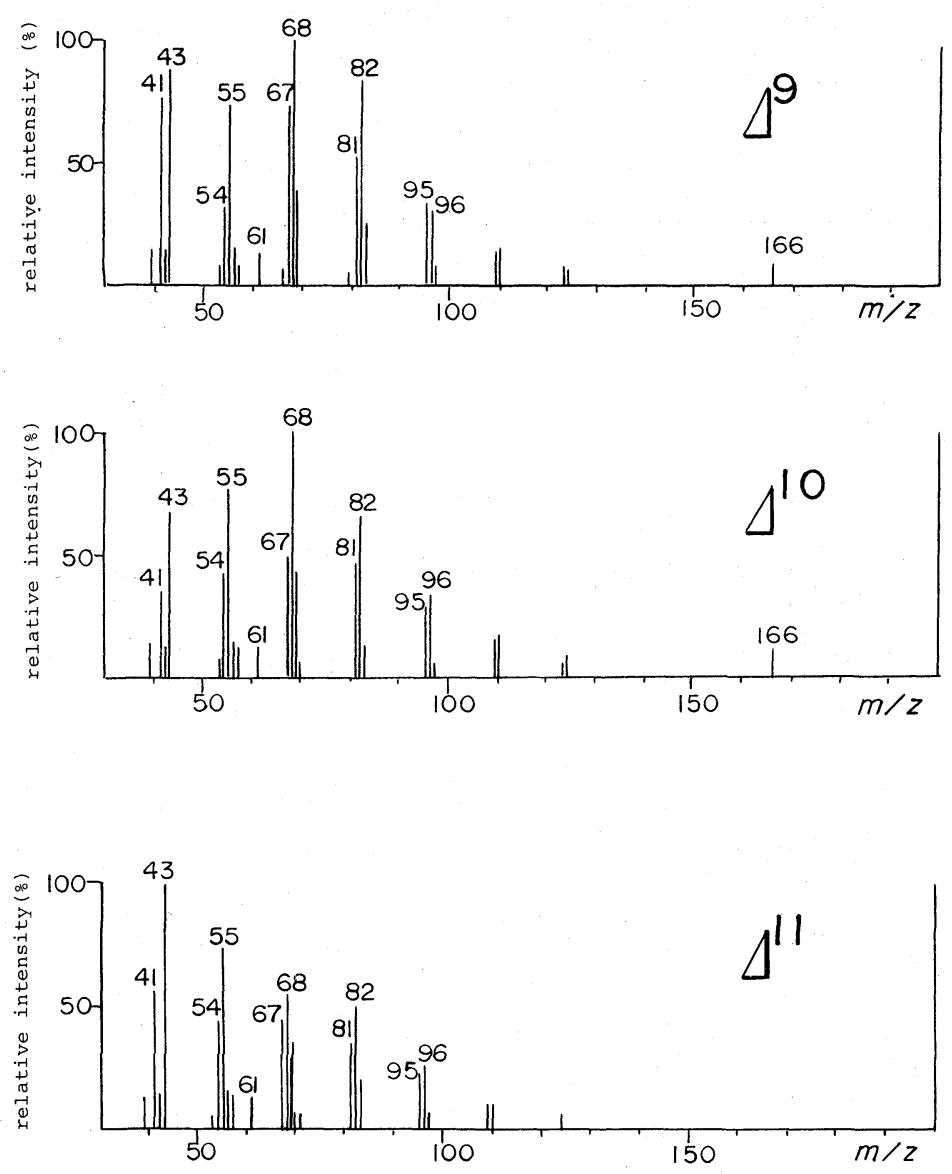

FIG. 1. Mass Spectra of Positional Isomers of Dodecenyl Acetate at $70 \mathrm{eV}$ Ionization Energy.

68, while $\Delta^{7}$ - and $\Delta^{8}$-isomers had dual base peaks at $m / z 43$ and 67, and at $m / z 43$ and 55, respectively.

The variation of ionization potential to $40 \mathrm{eV}$ had little effect upon each mass spectrum, but under mild ionization conditions of $20 \mathrm{eV}$, each mass spectrum showed closely similar cleavage patterns, in which the base peak of each isomers was at $m / z 82$.

Our five independent measurements suggest that the patterns of intensities of the predominant ions are governed by the original position of double bonds in the isomeric alkenes. Thus the intensity ratios of certain selected pairs of fragment ions give characteristic values, useful for locating the original position of double bonds in the present acetates.
Table I shows the ratios of the significant ion intensities which are of diagnostic value for the isolation of one particular isomer from the remainder, depending upon whether or not the value of the ratio is over unity.

The $\Delta^{5}-, \Delta^{6}$ - and $\Delta^{7}$-isomers can be characterized readily by the ratios of $m / z 54$ to 55 , $m / z 95$ to 96 and $m / z 81$ to 82 respectively. The $\Delta^{5}$-isomer was further distinguishable by the ratios of $m / z 41$ to 54 and $m / z 55$ to 81 , whose values were below unity. Although the value of $m / z 95$ to 96 was slightly over unity in $\Delta^{9}$ isomer and $\Delta^{5}$-one which has been set apart by the indices presented above, the ratios of $\mathrm{m} / \mathrm{z}$ 68 to 95 and $\mathrm{m} / \mathrm{z} 81$ to 95 isolated $\Delta^{6}$-isomer from the others, unambiguously.

The ratio of $m / z 67$ to 68 is of diagnostic value for the isolation of $\Delta^{9}-, \Delta^{10}$ - and $\Delta^{11}$ - 
Table I. The Ratios of Characteristic Peak Intensities of Positional Isomers of Dodecenyl ACETATe at $70 \mathrm{eV}$

\begin{tabular}{|c|c|c|c|c|c|c|c|}
\hline \multirow{2}{*}{$\begin{array}{c}\text { Ratio } \\
(m / z) /(m / z)\end{array}$} & \multicolumn{7}{|c|}{ Isomer $^{a, b}$} \\
\hline & $\Delta^{5}$ & $\Delta^{6}$ & $\Delta^{7}$ & $\Delta^{8}$ & $\Delta^{9}$ & $\Delta^{10}$ & $\Delta^{11}$ \\
\hline $41 / 54$ & $\begin{array}{c}0.76 \\
(0.06)\end{array}$ & $\begin{array}{c}1.17 \\
(0.18)\end{array}$ & $\begin{array}{c}1.26 \\
(0.20)\end{array}$ & $\begin{array}{c}1.74 \\
(-0.22)\end{array}$ & $\begin{array}{c}2.40 \\
(0.24)\end{array}$ & $\begin{array}{c}1.17 \\
(0.11)\end{array}$ & $\begin{array}{c}1.29 \\
(0.20)\end{array}$ \\
\hline $41 / 55$ & $\begin{array}{c}0.95 \\
(0.07)\end{array}$ & $\begin{array}{c}0.90 \\
(0.15)\end{array}$ & $\begin{array}{c}0.83 \\
(0.15)\end{array}$ & $\begin{array}{c}0.84 \\
(0.08)\end{array}$ & $\begin{array}{c}1.05 \\
(0.12)\end{array}$ & $\begin{array}{c}0.59 \\
(0.06)\end{array}$ & $\begin{array}{c}0.80 \\
(0.09)\end{array}$ \\
\hline $43 / 68$ & $\begin{array}{r}1.58 \\
( \pm 0.09)\end{array}$ & $\begin{array}{c}1.99 \\
(0.17)\end{array}$ & $\begin{array}{r}2.02 \\
(-0.07)\end{array}$ & $\begin{array}{c}1.93 \\
(-0.19)\end{array}$ & $\begin{array}{c}0.82 \\
( \pm 0.07)\end{array}$ & $\begin{array}{c}0.77 \\
( \pm 0.10)\end{array}$ & $\begin{array}{c}1.75 \\
(0.13)\end{array}$ \\
\hline $54 / 55$ & $\begin{array}{r}1.25 \\
(0.04)\end{array}$ & $\begin{array}{c}0.77 \\
(0.02)\end{array}$ & $\begin{array}{r}0.65 \\
( \pm 0.01)\end{array}$ & $\begin{array}{c}0.48 \\
(0.04)\end{array}$ & $\begin{array}{r}0.44 \\
(-0.02)\end{array}$ & $\begin{array}{c}0.51 \\
(0.04)\end{array}$ & $\begin{array}{r}0.62 \\
( \pm 0.04)\end{array}$ \\
\hline $54 / 81$ & $\begin{array}{l}1.18 \\
(0.09)\end{array}$ & $\begin{array}{c}0.94 \\
(-0.08)\end{array}$ & $\begin{array}{c}0.75 \\
(-0.04)\end{array}$ & $\begin{array}{c}0.67 \\
(0.09)\end{array}$ & $\begin{array}{r}0.61 \\
( \pm 0.02)\end{array}$ & $\begin{array}{c}0.87 \\
(-0.08)\end{array}$ & $\begin{array}{c}1.21 \\
(0.07)\end{array}$ \\
\hline $55 / 68$ & $\begin{array}{c}0.90 \\
(0.07)\end{array}$ & $\begin{array}{c}1.50 \\
(-0.08)\end{array}$ & $\begin{array}{c}1.89 \\
(0.15)\end{array}$ & $\begin{array}{c}1.93 \\
(-0.19)\end{array}$ & $\begin{array}{c}0.76 \\
(0.05)\end{array}$ & $\begin{array}{c}0.79 \\
( \pm 0.03)\end{array}$ & $\begin{array}{r}1.33 \\
( \pm 0.05)\end{array}$ \\
\hline $55 / 81$ & $\begin{array}{c}0.94 \\
(0.10)\end{array}$ & $\begin{array}{c}1.21 \\
(-0.08)\end{array}$ & $\begin{array}{c}1.15 \\
( \pm 0.03)\end{array}$ & $\begin{array}{c}1.38 \\
(-0.13)\end{array}$ & $\begin{array}{c}1.40 \\
(-0.12)\end{array}$ & $\begin{array}{c}1.71 \\
(-0.07)\end{array}$ & $\begin{array}{r}1.96 \\
(-0.15)\end{array}$ \\
\hline $67 / 68$ & $\begin{array}{c}1.34 \\
(-0.04)\end{array}$ & $\begin{array}{c}2.26 \\
(0.07)\end{array}$ & $\begin{array}{c}2.02 \\
(0.11)\end{array}$ & $\begin{array}{c}1.82 \\
(-0.07)\end{array}$ & $\begin{array}{c}0.73 \\
( \pm 0.01)\end{array}$ & $\begin{array}{c}0.51 \\
( \pm 0.02)\end{array}$ & $\begin{array}{c}0.82 \\
(0.05)\end{array}$ \\
\hline $67 / 82$ & $\begin{array}{c}1.21 \\
(0.05)\end{array}$ & $\begin{array}{c}1.41 \\
(0.09)\end{array}$ & $\begin{array}{c}1.37 \\
(0.07)\end{array}$ & $\begin{array}{c}1.04 \\
(-0.08)\end{array}$ & $\begin{array}{c}0.88 \\
(-0.07)\end{array}$ & $\begin{array}{c}0.78 \\
(0.06)\end{array}$ & $\begin{array}{c}0.86 \\
(0.05)\end{array}$ \\
\hline $68 / 95$ & $\begin{array}{c}1.21 \\
(-0.05)\end{array}$ & $\begin{array}{c}0.73 \\
(-0.03)\end{array}$ & $\begin{array}{c}1.15 \\
(-0.06)\end{array}$ & $\begin{array}{c}1.27 \\
(-0.12)\end{array}$ & $\begin{array}{c}3.01 \\
(-0.19)\end{array}$ & $\begin{array}{c}3.62 \\
(0.21)\end{array}$ & $\begin{array}{r}2.18 \\
( \pm 0.13)\end{array}$ \\
\hline $69 / 95$ & $\begin{array}{c}0.54 \\
(0.06)\end{array}$ & $\begin{array}{c}0.56 \\
(-0.04)\end{array}$ & $\begin{array}{c}0.77 \\
(-0.09)\end{array}$ & $\begin{array}{c}0.86 \\
(0.19)\end{array}$ & $\begin{array}{c}1.21 \\
(0.15)\end{array}$ & $\begin{array}{c}1.50 \\
(-0.11)\end{array}$ & $\begin{array}{r}1.50 \\
(-0.13)\end{array}$ \\
\hline $81 / 82$ & $\begin{array}{c}0.86 \\
(0.06)\end{array}$ & $\begin{array}{c}0.77 \\
(0.06)\end{array}$ & $\begin{array}{c}1.12 \\
(-0.06)\end{array}$ & $\begin{array}{c}0.80 \\
(-0.07)\end{array}$ & $\begin{array}{c}0.65 \\
(-0.06)\end{array}$ & $\begin{array}{c}0.71 \\
(0.04)\end{array}$ & $\begin{array}{r}0.70 \\
(-0.04)\end{array}$ \\
\hline $81 / 95$ & $\begin{array}{c}1.15 \\
(0.12)\end{array}$ & $\begin{array}{c}0.90 \\
(-0.06)\end{array}$ & $\begin{array}{c}1.91 \\
(-0.12)\end{array}$ & $\begin{array}{c}1.78 \\
(-0.13)\end{array}$ & $\begin{array}{r}1.64 \\
( \pm 0.05)\end{array}$ & $\begin{array}{c}1.67 \\
(0.09)\end{array}$ & $\begin{array}{c}1.47 \\
(0.07)\end{array}$ \\
\hline $95 / 96$ & $\begin{array}{c}1.06 \\
(-0.08)\end{array}$ & $\begin{array}{c}1.85 \\
(-0.12)\end{array}$ & $\begin{array}{c}0.83 \\
(0.06)\end{array}$ & $\begin{array}{c}0.83 \\
(-0.06)\end{array}$ & $\begin{array}{c}1.08 \\
(-0.05)\end{array}$ & $\begin{array}{c}0.90 \\
(0.04)\end{array}$ & $\begin{array}{c}0.96 \\
(0.04)\end{array}$ \\
\hline
\end{tabular}

$a$ Values are the average of five independent determinations.

$b$ Maximum deviation values are given in parentheses.

isomers from the remainder. Among these three isomers, which may also be characterized by the ratios of $m / z 67$ to 82 and $m / z 69$ to 95 , $\Delta^{11}$-isomer has a characteristic series of indices, namely $m / z 43$ to $68, m / z 54$ to 81 and $m / z 55$ to 68 . The distinction between $\Delta^{9}$ - and $\Delta^{10}$-isomers may be drawn by the values of the two ratios of $m / z 41$ to 55 and $m / z 95$ to 96 .

In the present system, outstanding indices for the rapid identification of the $\Delta^{8}$-isomer remains obscure, so that we are now in the situation to characterize the other isomers in order to leave the $\Delta^{8}$-isomer.

Table II shows the effect of the ionization potential on six indices, which are essential for the isolation of a given isomer from the re- mainder. These indices are substantially effective to locate the double bond position over a range of 70 to $40 \mathrm{eV}$. The other indices listed in Table I are essentially similar to the situation of the indices in Table II.

Table III shows some indices obtained with a double focusing instrument, which may afford an abundance pattern different from that of a single focusing system. These indices are almost consistent with the data given in Table I, and may be submitted to determination of a double bond position by employing the ratios of $m / z 54$ to 55 for $\Delta^{5}$-isomer, $m / z 68$ to $95, m / z$ 81 to 95 and $m / z 95$ to 96 for $\Delta^{6}$-isomer, $m / z 81$ to 82 for $\Delta^{7}$-isomer, $m / z 67$ to 68 for $\Delta^{9}-, \Delta^{10}$ and $\Delta^{11}$-isomers, and $m / z 43$ to 68 and $m / z 55$ 
TABle II. EFfects of Ionization ENERgy ON THE Ratios of Characteristic Peak Intensities

\begin{tabular}{|c|c|c|c|c|c|c|c|c|}
\hline \multirow{2}{*}{$\begin{array}{c}\text { Ratio } \\
(m / z) /(m / z)\end{array}$} & \multirow{2}{*}{$\mathrm{eV}$} & \multicolumn{7}{|c|}{ Isomer } \\
\hline & & $\Delta^{5}$ & $\Delta^{6}$ & $\Delta^{7}$ & $4^{8}$ & $\Delta^{9}$ & $\Delta^{10}$ & $\Delta^{11}$ \\
\hline \multirow{5}{*}{$43 / 68$} & $60^{a}$ & 1.55 & 2.01 & 2.07 & 1.98 & 0.84 & 0.77 & 1.59 \\
\hline & $50^{b}$ & 1.45 & 1.86 & 1.89 & 1.63 & 0.77 & 0.71 & 1.48 \\
\hline & $40^{a}$ & 1.12 & 1.57 & 1.62 & 1.38 & 0.65 & 0.62 & 1.19 \\
\hline & $30^{b}$ & 0.71 & 0.95 & 0.90 & 0.88 & 0.39 & 0.34 & 0.75 \\
\hline & $20^{a}$ & 0.20 & 0.25 & 0.35 & 0.22 & 0.11 & 0.10 & 0.27 \\
\hline \multirow{5}{*}{$54 / 55$} & $60^{a}$ & 1.30 & 0.82 & 0.62 & 0.50 & 0.45 & 0.52 & 0.63 \\
\hline & $50^{b}$ & 1.20 & 0.77 & 0.67 & 0.50 & 0.43 & 0.53 & 0.64 \\
\hline & $40^{a}$ & 1.19 & 0.79 & 0.67 & 0.51 & 0.45 & 0.53 & 0.66 \\
\hline & $30^{b}$ & 1.40 & 0.84 & 0.75 & 0.58 & 0.45 & 0.64 & 0.77 \\
\hline & $20^{a}$ & 2.44 & 1.33 & 1.26 & 0.88 & 0.77 & 1.35 & 1.45 \\
\hline \multirow{5}{*}{$67 / 68$} & $60^{a}$ & 1.36 & 2.28 & 1.96 & 1.87 & 0.73 & 0.50 & 0.84 \\
\hline & $50^{b}$ & 1.32 & 2.29 & 2.04 & 1.79 & 0.72 & 0.49 & 0.82 \\
\hline & $40^{a}$ & 1.23 & 2.19 & 1.98 & 1.75 & 0.70 & 0.49 & 0.75 \\
\hline & $30^{b}$ & 1.15 & 2.05 & 1.86 & 1.59 & 0.62 & 0.44 & 0.71 \\
\hline & $20^{a}$ & 0.82 & 1.77 & 1.53 & 1.53 & 1.27 & 0.44 & 0.53 \\
\hline \multirow{5}{*}{$68 / 95$} & $60^{a}$ & 1.25 & 0.76 & 1.22 & 1.31 & 3.11 & 3.58 & 1.96 \\
\hline & $50^{b}$ & 1.28 & 0.74 & 1.19 & 1.29 & 3.13 & 3.49 & 2.03 \\
\hline & $40^{a}$ & 1.24 & 0.73 & 1.18 & 1.29 & 2.96 & 3.58 & 2.12 \\
\hline & $30^{b}$ & 1.17 & 0.70 & 1.11 & 1.23 & 2.96 & 3.35 & 1.99 \\
\hline & $20^{a}$ & 1.16 & 0.61 & 0.89 & 1.17 & 2.89 & 3.28 & 1.87 \\
\hline \multirow{5}{*}{$81 / 82$} & $60^{a}$ & 0.89 & 0.78 & 1.15 & 0.81 & 0.67 & 0.70 & 0.68 \\
\hline & $50^{b}$ & 0.88 & 0.75 & 1.09 & 0.81 & 0.65 & 0.69 & 0.75 \\
\hline & $40^{a}$ & 0.84 & 0.73 & 1.08 & 0.78 & 0.64 & 0.70 & 0.70 \\
\hline & $30^{b}$ & 0.79 & 0.70 & 1.03 & 0.75 & 0.62 & 0.66 & 0.67 \\
\hline & $20^{a}$ & 0.57 & 0.38 & 0.79 & 0.62 & 0.48 & 0.55 & 0.49 \\
\hline \multirow{5}{*}{$95 / 96$} & $60^{a}$ & 1.06 & 1.73 & 0.83 & 0.85 & 1.04 & 0.89 & 0.93 \\
\hline & $50^{b}$ & 1.04 & 1.73 & 0.82 & 0.83 & 1.02 & 0.91 & 0.92 \\
\hline & $40^{a}$ & 1.03 & 1.75 & 0.84 & 0.81 & 1.05 & 0.89 & 0.87 \\
\hline & $30^{b}$ & 1.00 & 1.66 & 0.80 & 0.79 & 1.00 & 0.86 & 0.87 \\
\hline & $20^{a}$ & 0.83 & 1.39 & 0.70 & 0.65 & 0.81 & 0.77 & 0.75 \\
\hline
\end{tabular}

a Values are the average of three independent determinations.

$b$ Values are the average of five independent determinations.

Table III. The Ratios of Characteristic Peak Intensities with Double Focusing Mass SPeCtrometry at $70 \mathrm{eV}$

\begin{tabular}{cccccccc}
\hline $\begin{array}{c}\text { Ratio } \\
(m / z) /(m / z)\end{array}$ & \multicolumn{9}{c}{ Isomer } \\
\cline { 2 - 7 } & $\Delta^{5}$ & $\Delta^{6}$ & $\Delta^{7}$ & $\Delta^{8}$ & $\Delta^{9}$ & $\Delta^{10}$ & $\Delta^{11}$ \\
\hline $43 / 68$ & 0.85 & 0.86 & 1.06 & 0.56 & 0.45 & 0.66 & 1.20 \\
$54 / 55$ & 1.19 & 0.86 & 0.63 & 0.63 & 0.47 & 0.49 & 0.62 \\
$55 / 68$ & 0.67 & 1.16 & 1.64 & 1.18 & 0.61 & 0.99 & 1.43 \\
$67 / 68$ & 1.04 & 1.95 & 1.88 & 1.43 & 0.72 & 0.69 & 0.98 \\
$68 / 95$ & 1.25 & 0.74 & 1.04 & 1.13 & 2.32 & 2.99 & 1.90 \\
$81 / 82$ & 0.74 & 0.71 & 1.04 & 0.84 & 0.63 & 0.93 & 0.90 \\
$81 / 95$ & 1.16 & 0.96 & 2.01 & 1.63 & 1.56 & 1.78 & 1.58 \\
$95 / 96$ & 0.86 & 1.58 & 0.70 & 0.81 & 0.90 & 1.11 & 1.05 \\
\hline
\end{tabular}


to 68 for $\Delta^{11}$-isomer. However, it should be noted that certain indices, e.g., $m / z 41$ to 54 and $m / z 41$ to 55 , are different from those of the present single focusing system, so the application of the present indices to different kinds of systems should be studied further.

\section{REFERENCES}

1) M. Jacobson, "Insect Sex Pheromones," Academic Press, New York and London, 1972, pp. 170 193.

2) P. Capella and C. M. Zorzut, Anal. Chem., 40, 1458
(1968).

3) For example, M. Beroza and B. A. Biel, Anal. Chem., 39, 1131 (1967); C. Hirano, H. Muramoto and M. Horiike Naturwissenchaften, 63, 439 (1976).

4) M. Horiike, N. Miyata and C. Hirano, Biomed. Mass Spectrom., 8, 41 (1981).

5) R. S. Berger, Ann. Entomol. Soc. Am., 59, 766 (1966).

6) W. L. Roelofs, A. Comeau and R. Solle, Nature, 224, 723 (1969).

7) W. L. Roelofs, J. P. Tette, E. F. Taschenberg and A. Comeau J. Insect Physiol., 17, 2235 (1971).

8) M. Horiike and C. Hirano, Agric. Biol. Chem., 44, 2229 (1980) and references cited therein. 